\title{
AS JOVENS RURAIS QUE ESTUDAM NA ETEC JALES (SP): RELAÇÕES FAMILIARES E PROJETOS DE VIDA
}

\author{
Ana Heloisa Maia ${ }^{1}$, Antonio Lázaro Sant' $\mathrm{Ana}^{2}$, Gabriela dos Santos Souza ${ }^{3}$, Flaviana \\ Cavalcanti da Silva ${ }^{4}$
}

${ }^{1}$ Docente da Universidade do Estado do Mato Grosso e Doutoranda em Agronomia na Faculdade de Engenharia / UNESP Campus de Ilha Solteira (SP).

${ }^{2}$ Professor Adjunto (Livre Docente) da Faculdade de Engenharia / UNESP Campus de Ilha Solteira (SP).

${ }^{3}$ Mestre em Agronomia / UNESP Campus de Ilha Solteira (SP).

${ }^{4}$ Doutoranda em Agronomia na Faculdade de Engenharia / UNESP Campus de Ilha Solteira (SP).

RESUMO: Diversos estudos têm revelado que há uma tendência do jovem rural em sair do campo em busca de melhores oportunidades na cidade, principalmente as jovens. Este artigo visa analisar os fatores que influenciam a permanência ou a desvinculação do trabalho na terra por parte das jovens, filhas de agricultores familiares e alunas da Etec Jales (SP), com base nas relações familiares, no estudo e seus planos futuros. Foi aplicado um questionário às alunas da Etec Jales, com questões específicas dirigidas às alunas ligadas à agropecuária, visando caracterizar a família e a unidade de produção agropecuária, além de informações sobre o trabalho, o estudo, o lazer e as demais atividades realizadas pelas jovens, sua participação nas decisões familiares relativas à unidade agropecuária familiar; seus planos e projetos de vida. Aos pais das alunas foram abordadas questões relativas à Etec Jales, o que pensavam do futuro das filhas e da sucessão da propriedade, além de buscar avaliar o grau de satisfação dos pais em relação ao trabalho e à vida rural. Pode-se verificar que as jovens estudantes da Etec Jales têm no prolongamento da escolarização a busca por melhores condições de vida, assim as mesmas não têm a intenção de assumir a propriedade dos pais e seus planos futuros se remetem a fazer um curso superior ou conseguir um emprego fora do meio rural. Este fato pode comprometer a reprodução da agricultura familiar, sendo necessárias políticas públicas que incentivem a ampliação da autonomia dessas jovens no meio em que vivem.

Palavras-chave: Jovens rurais. Agricultura familiar. Escola técnica de nível médio. Gênero.

\section{THE RURAL YOUTH TO STUDY IN ETEC JALES: FAMILY RELATIONSHIPS AND PROJECTS OF LIFE}

\begin{abstract}
Several studies have shown that there is a tendency for rural youth to leave the field in search of better opportunities in the city, especially the young. This article aims to analyze the factors that influence the permanence or disconnection from the land by the young daughters of farmers and students of Etec Jales (SP), based on family relationships, the study and future plans. A questionnaire was given to students of Etec Jales, with specific questions addressed the students linked to agriculture, in order to characterize the family unit and the agricultural production, as well as information on work, study, leisure and other
\end{abstract}

Cultura Agronômica, Ilha Solteira, v.24, n.3, p.345-360, 2015 
activities undertaken by young people, their participation in family decisions concerning the family farming unit, their plans and aspirations. Parents of students were addressed issues Etec Jales, what they thought the future of children and succession of ownership, and try to assess the degree of parental satisfaction in relation to work and rural life. You can check that young students have Etec Jales extension of schooling in the quest for better living conditions, so they do not intend to take ownership of parents and their future plans are to refer to a college or get employment outside the rural areas. This may impair the reproduction of family farming, and public policies necessary to encourage the expansion of the autonomy of these young people in their realm.

Key words: Rural youth. Familiar agriculture. Technical school middle level. Gender.

\section{INTRODUÇÃO}

Diversos estudos têm revelado que há uma tendência do jovem rural em sair do campo em busca de melhores oportunidades na cidade, principalmente em relação ao estudo, trabalho, relações sociais, entre outros. Esse processo é ainda maior entre as jovens, o que tem levado a preocupação de diversos pesquisadores da área em relação ao futuro da agricultura familiar.

Para Carneiro (1998) a migração temporária ou o deslocamento de jovens rurais para a cidade, sobretudo com o objetivo de estudar, pode gerar sentimentos de pertencimento múltiplos, bem como, a possibilidade da construção de individualidades e realização de projetos pessoais que podem se ajustar ao compromisso familiar de dar continuidade às atividades agrícolas. No entanto, nem sempre isto é verificado no caso das meninas, uma vez que as relações de gêneros existentes no meio rural passam a determinar sua permanência ou não no local. Como a maioria das jovens não tem perspectiva de ser incluída na sucessão da propriedade e sua participação nas decisões familiares é ínfima, estas passam a traçar planos que geralmente não estão ligados ao meio onde vivem.

$\mathrm{O}$ acesso ao estudo para as moças vai muito além da conquista da independência familiar e da possibilidade de emprego na cidade, uma vez que a formação educacional fortalece seus planos futuros:

(...) com amplitudes que se estendem até outras
dimensões do campo profissional e da vida, vendo no
acesso aos estudos a possibilidade de questionar padrões,
conceitos e comportamentos, sobretudo aqueles que
restringem a sua liberdade no espaço rural
(STROPASOLAS, 2006, p. 306).

Este artigo visa analisar os fatores que influenciam a permanência ou a desvinculação do trabalho na terra por parte das jovens, filhas de agricultores familiares e alunas da Escola Técnica Estadual “Dr. José Luiz Viana Coutinho" de Jales - SP (Etec Jales), com base nas relações familiares, no estudo e em seus planos de engajamento profissional e de moradia.

Cultura Agronômica, Ilha Solteira, v.24, n.3, p.345-360, 2015 


\section{MATERIAL E MÉTODOS}

Em termos de técnicas de pesquisa, inicialmente foi realizada uma revisão bibliográfica sobre as jovens rurais e sobre metodologias de pesquisa consideradas mais adequadas para a abordagem deste segmento social. Foram realizados levantamento e sistematização de dados gerais sobre a região de Jales, particularmente de aspectos ligados ao meio rural e as jovens, e, por meio de visitas específicas, foi feita a caracterização da Etec de Jales e de seus alunos. Também foram coletados dados secundários de instituições como a Centro Paula Souza, o IBGE (Instituto Brasileiro de Geografia e Estatística), a CATI (Coordenadoria de Assistência Técnica Integral) e a Fundação Seade (Fundação Sistema Estadual de Análise de Dados).

O questionário, aplicado a 13 alunas da Etec Jales, possuía algumas questões específicas dirigidas às alunas ligadas à agropecuária, visando caracterizar a família e a unidade de produção agropecuária (o conhecimento das jovens sobre a mesma), além de informações sobre o trabalho, o estudo, o lazer e as demais atividades realizadas pelas jovens, sua participação nas decisões familiares relativas à unidade agropecuária familiar; seus planos e projetos de vida. Em seguida os dados dos questionários foram tabulados e analisados de forma preliminar, visando definir os temas e questões a serem tratados nas entrevistas coletivas com os pais dos(as) alunos(as). As entrevistas com o grupo de meninas também foram gravadas com o intuito de captar todos os aspectos não explicitados durante a aplicação dos questionários, que poderiam contribuir para o entendimento do universo dessas jovens. Foram também entrevistados os pais das alunas, momento em que foram abordadas questões relativas à Etec Jales, o que pensavam do futuro das filhas e da sucessão da propriedade, e também buscou-se avaliar o grau de satisfação dos pais em relação ao trabalho e a vida rural. As entrevistas com os pais das alunas foram realizadas nas propriedades rurais. Também foi realizada uma entrevista gravada com o Diretor da Etec Jales, Luiz Carlos Floriano da Silva, na qual foram tratados de aspectos gerais da Escola, com algumas questões específicas sobre os temas de interesse da pesquisa.

Após o trabalho de campo, os dados das entrevistas foram transcritos e os questionários tabulados e analisados para redigir este artigo.

\section{Características da região de Jales}

A região Jales ${ }^{1}$ situa-se no extremo noroeste do Estado de São Paulo e é formada por 22 municípios que possuem, aproximadamente, 319.420,4 hectares e 9.464 propriedades agrícolas, sendo que somente o município de Jales abrange 1.248 propriedades que ocupam 33.542,2 hectares (SÃO PAULO, 2008). Há predomínio de pequenas propriedades, como se pode constatar pelos dados do Lupa 2008: 87,5\% das propriedades do EDR de Jales possuem menos de 50 ha e ocupam $40 \%$ da área total. Se considerarmos as unidades de produção agropecuária até 100ha, que corresponde aproximadamente a 4 módulos fiscais da

1 A região de Jales considerada neste trabalho é a Região de Governo, pois esta é a mesma divisão territorial adotada pela Cati, com a denominação de Escritório de Desenvolvimento Rural (EDR), no censo do LUPA, o que facilita a comparação dos dados.

Cultura Agronômica, Ilha Solteira, v.24, n.3, p.345-360, 2015 
maioria dos municípios (o módulo fiscal na região de Jales situa-se na faixa de 26 à 30 hectares), estas ocupam 53,8\% da área e 94,3\% do número total.

Segundo Petinari et al. (2008) a região tem sua economia essencialmente agrícola, desde o início da colonização, os produtores tinham suas atividades voltadas para a agricultura, tais como a bovinocultura e a cafeicultura. Atualmente, a fruticultura é uma das atividades que vem ganhando importância no município, em termos de valor da produção, com destaque para a uva de mesa, que é a principal atividade econômica, seguida da laranja, limão e outras (TONDATO et al., 2010).

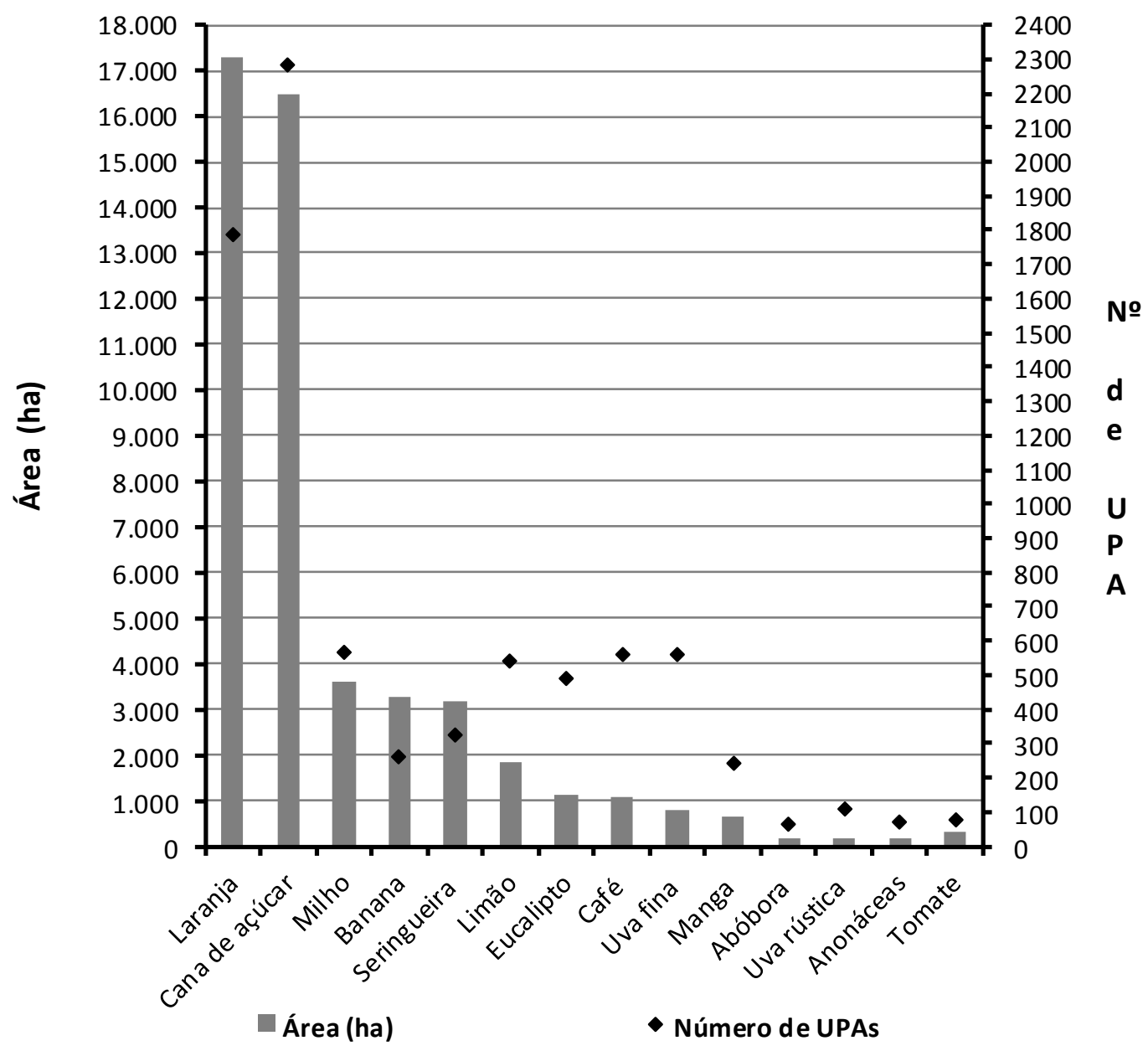

Figura 1. Principais explorações vegetais, em termos de número de UPAs (Unidades de Produção Agropecuárias) e área total (ha), no Escritório de Desenvolvimento Rural de Jales. Fonte: Adaptado de SÃO PAULO (2008).

A cultura do café foi durante várias décadas a principal atividade econômica da região, mas a decadência deste a partir dos anos 1980 e a predominância da produção familiar baseada na pequena propriedade (a parceria era menos importante do que em outras regiões) contribuíram para que opções intensivas em mão-de-obra fossem adotadas. Atualmente a região caracteriza-se por grande diversidade em termos produtivos, com destaque para a presença de diversas frutíferas e da pecuária de leite. No entanto, em termos 
de área ocupada, há predominância das pastagens (bovinocultura), seguida da laranja, canade-açúcar, milho e seringueira. As culturas da cana e seringueira têm apresentado crescimento significativo nessa última década. São também importantes, do ponto de vista econômico e social, a uva fina, a banana, o limão, a manga, a uva rústica (niagara) e as anonáceas (pinha, fruta do conde, graviola, entre outras) (Figura 1).

\section{Características da Escola Técnica Estadual de Jales (SP)}

A Escola Técnica Estadual de Jales "Dr. José Luiz Viana Coutinho" (Etec Jales) foi instalada em 1989 com a missão de contribuir para um processo de transformação e desenvolvimento da denominada Região Geoeconômica dos Grandes Lagos (Ilha Solteira, Três Irmãos e Água Vermelha), no extremo noroeste do Estado de São Paulo, aproveitando e potencializando os recursos e a vocação econômica local, predominantemente agropecuária (CENTRO PAULA SOUZA, 2008). Foi implantada a três quilômetros do centro da cidade de Jales, em área total de aproximadamente 50 hectares.

A infraestrutura instalada é de mais de três mil metros quadrados de área construída, voltada para a exploração das atividades agropecuária, à qual recentemente integrou-se a preocupação com a agregação das tecnologias agroindustriais, de informática e de cursos ligados ao setor de serviços (ETEC JALES, 2010).

Na Etec Jales são ministrados 10 cursos de Ensino Técnico e há também uma classe de Ensino Médio regular (extinta a partir de 2010, mas que ainda possui turmas cursando o $2^{\circ}$ e $3^{\circ}$ anos). Os cursos englobam diversas áreas do conhecimento, mas com concentração em cursos técnicos ligados à agropecuária. Quatro deles são no período diurno: Técnico em Produção Agropecuária Integrado ao Ensino Médio (36 meses - período integral); Técnico em Agropecuária (18 meses); Técnico em Produção de Cana-de-açúcar - parte do curso é ministrado à noite também - (duração de 18 meses), além do Ensino Médio regular (até 2011). Outros sete cursos são ministrados no período noturno: Técnico em Agroindústria (18 meses); Técnico em Agronegócio (18 meses); Técnico em Alimentos (18 meses); Técnico em Informática (18 meses); Técnico em Marketing (18 meses); Técnico em Comércio (18 meses); Técnico em Informática para Internet (18 meses). Todos os cursos oferecem 40 vagas anualmente (ETEC JALES, 2010). Há também extensões da Etec Jales em um bairro urbano de Jales, onde são oferecidos, no período noturno, os cursos de Administração, Contabilidade e Secretariado; no município de Sud Mennucci, onde há os cursos de Informática e Administração; e em Santa Rita D’Oeste, onde é oferecido o curso de Agronegócio.

A Etec Jales dispõe de 125 vagas no alojamento, localizado na própria área da Escola. Os internos são todos do sexo masculino. A falta de vagas femininas pode ser um dos entraves ao ingresso de alunas do sexo feminino nos cursos técnicos da Etec Jales. O ingresso é realizado por meio de vestibulinho (prova semelhante ao vestibular que visa classificar os candidatos com melhores notas) em todos os cursos.

Cultura Agronômica, Ilha Solteira, v.24, n.3, p.345-360, 2015 


\section{RESULTADOS E DISCUSSÃO}

\section{As jovens e as relações familiares}

O cotidiano das jovens rurais é marcado pela escola e pelo lar, para Pais (2003) conhecer as singularidades do cotidiano dessas jovens é fundamental para compreendermos a percepção e a ação destas sobre o meio em que estão inseridas. Neste caso, quando estão na propriedade as atividades que desenvolvem se limitam aos afazeres domésticos ou ao "auxílio" na colheita, desbrota, pulverizações com agrotóxicos, ordenha e trato dos animais, etc. A autonomia no desenvolvimento das atividades na propriedade pelas meninas depende das relações patriarcais estabelecidas e geralmente atividades que não incluem valor monetário, são destinadas as meninas.

Eu gostava quando eu estava em casa, eu de manhã ia ajudar o meu pai tirar o leite, às vezes ele me deixava chegar perto das vacas, andava no sítio e a tarde ia para escola... Eu tinha muito contato com o sítio, mas eu tinha pouco contato com a profissão... a terra... porque eu era muito nova... (aluna 48, 16 anos, Jales ${ }^{2}$ )

Quando eu estou em casa eu aproveito para acordar um pouco mais tarde né... começo a arrumar a casa, ajudar minha mãe nas atividades domésticas, assisto televisão $e$ durmo muito... não ajudo meu pai nas atividades rurais, meu irmão que ajuda, mas sempre estou informada. (aluna 34, 16 anos, Palmeira D’Oeste)

Muitas meninas declararam que não são levadas a sério nas relações de trabalho dentro da propriedade, e esta diferença de tratamento tem provocado o desinteresse das mesmas pelas atividades desenvolvidas na propriedade. As meninas acabam fazendo as atividades por considerarem uma "obrigação" ou uma "dívida" para com a família. Às vezes deixam de realizar as tarefas. A principal reclamação, no entanto, é que não são ouvidas como alguém que está adquirindo uma qualificação técnica específica:

(...) Nem falo, meu pai é assim, tanta experiência em campo... eu sou uma menina dentro de casa, ele gosta do que eu tô fazendo [o curso técnico], mas minha opinião não conta. (aluna 34, 16 anos, Palmeira D’Oeste)

Tem algumas pessoas da família que tem sítio, aí você fala... Ah, você poderia fazer assim para melhorar, mas não dá muita credibilidade pelo fato de ser menina, mesmo sabendo que você está fazendo um curso técnico. (aluna 48,16 anos, Jales)

Brumer (2006) aponta em suas pesquisas para a insatisfação dos jovens por não participarem das decisões familiares, essa exclusão segundo a autora seria ainda maior no

2 O número do filho corresponde ao número do questionário que responderam, acrescidos da idade dos mesmos, na época em que responderam ao questionário, e do município onde a família reside. Os pais entrevistados serão identificados a partir dos filhos e do município em que moram.

Cultura Agronômica, Ilha Solteira, v.24, n.3, p.345-360, 2015 
caso das mulheres. Em estudo realizado por Martins (2008), com jovens de um assentamento rural no Rio de Janeiro, foi verificado que a inviabilidade (e invisibilidade) em muitos casos de formulação de projetos relacionados à agricultura e ao meio rural por parte das jovens está associada tanto ao seu lugar no assentamento e quanto na família. Dessa forma, observa-se que as relações familiares têm um papel importante na construção das trajetórias dessas jovens e quando as mesmas passam a não ser ouvidas pela família, o estímulo de permanência na propriedade é comprometido.

Em relação à participação das decisões relativas à propriedade as mais citadas pelas 13 jovens pesquisadas foram: a) aspectos técnicos da condução das culturas e criações (9); b) distribuição de serviços (7); c) quais investimentos devem ser feitos (7); d) a introdução de novas culturas e criações (4); e) necessidade ou não de financiamento agrícola (4); f) venda dos produtos e para quem será vendido (3). Duas das entrevistadas citaram que não participam de nenhuma decisão em relação à propriedade. Apesar dessas respostas indicarem alguma participação nas decisões, isso se dá mais como emissão de opinião, mas a influência dos pais é muito forte e a participação efetiva destas jovens na tomada de decisão é pequena ou quase nula, fato este que influência na decisão de sair do meio rural, em busca de independência e novas oportunidades, na grande maioria dos casos, não relacionadas ao seu modo de vida rural.

Lá em casa é meu pai, ninguém coloca na cabeça dele, pra ele é daquele jeito, ele não escuta, mais eu: a menina... (aluna 34, 16 anos, Palmeira D’Oeste)

Ah, por ser menina tem muito problema... e o pai não admite porque é menina... 'eu sou homem, sou o dono da casa, eu cresci no sítio, eu sei fazer tudo isso, agora vem você com dois, três anos de curso querer mudar do jeito que está'... (aluna 48, 16 anos, Jales)

Há casos, no entanto, em que o diálogo com os pais é mais aberto, o que permite uma inserção maior da jovem na propriedade.

No meu caso é um pouco diferente, eles sempre deram credibilidade, quando ele vai trabalhar, eu falo, pai me leva junto, me ensina até do jeito dele... quando eu chego em casa, se vão fazer qualquer coisa eles perguntam a opinião pra mim ... como faz? Eles fazem do jeito que eu falo, juntam minha opinião ao jeito deles e eles fazem... às vezes eles deixam pra fazer no final de semana que eu tô lá pra fazer junto... (aluna 36, 16 anos, Três Fronteiras)

Quem mora na propriedade? (pesquisador)

Eu, meu pai, minha irmã e minha mãe. (aluna 36, 16 anos, Três Fronteiras)

Você acha que se você tivesse um irmão, seria do mesmo jeito? (Pesquisador)

Cultura Agronômica, Ilha Solteira, v.24, n.3, p.345-360, 2015 
Ah,... não sei... eu acho que ia acabar escutando, porque eles têm uma cabeça muito aberta. (aluna 36, 16 anos, Três Fronteiras)

Em relação às atividades desenvolvidas na propriedade, geralmente quem define o que será feito é a figura paterna, embora muitas das jovens tenham vontade de aplicar os conhecimentos adquiridos em sala de aula na propriedade, as mesmas esbarram em alguns fatores relacionados à distinção de sexo, idade, confiança, saber próprio e falta de recursos financeiros, que determinam a não aceitação de suas idéias pelos pais.

Meu pai diz assim... quando você tiver a sua
propriedade, você faz o que você quiser com a tua,
enquanto eu estiver com a minha propriedade, vai ser do
meu jeito... é desse jeito e acabou!... (aluna 11,17 anos,
Santa Salete)

Segundo Menezes (2009) a influência da família no processo formativo do jovem tem implicações no conhecimento que este adquire desde muito cedo, quando começa a ser incorporado como força de trabalho no núcleo familiar, tendo em vista as necessidades de mão de obra para o desenvolvimento das atividades. No entanto, o envolvimento nas atividades de campo na propriedade ocorre mais tarde para as meninas, ou muitas vezes nem ocorre.

As melhorias na propriedade podem ser um importante fator na qualidade de vida dessas jovens, uma vez que a falta de infraestrutura básica e recursos financeiros têm influência na decisão entre "ficar" e "sair" do meio rural (CASTRO, 2004). Para as jovens pesquisadas aspectos relacionados aos investimentos no manejo de culturas e animais, à agregação de valor aos produtos e ao uso de novas tecnologias são importantes para aumentar a produtividade agrícola e obter maior renda da produção, no entanto, a aplicação dessas melhorias é influenciada pela falta de recursos financeiros e também pela necessidade destas mudanças serem bem vistas pelos pais.

A partir do depoimento de um dos pais, no que refere ao questionamento "Se a filha trouxe técnicas ou ideias que podem ser utilizadas na propriedade?", pode-se verificar que a falta de recursos financeiros foi um fator determinante para não implantação de melhorias relacionadas à propriedade:

Já deu [sugestão de mudanças na propriedade], mas a
gente não tem como investir... ficou só nas idéias. (pai da
aluna 34,16 anos, Palmeira D’Oeste)
O que você acha que mais impediu? (pesquisador)
Foi a questão do dinheiro... (pai da aluna 34,16 anos,
Palmeira D’Oeste)

Algumas pesquisas revelam que o abandono do campo por parte das jovens, muitas vezes é influenciado pela exclusão das filhas do processo de sucessão. Na medida em que as jovens não possuem perspectivas de assumir a propriedade, a saída da propriedade se torna uma forma de ganhar autonomia e independência em relação aos pais. 
Segundo Abramovay (1998):

(...) é preciso diferenciar as situações nas quais a agricultura e o meio rural para os jovens são uma escolha preferencial daquelas que resultam, na verdade, da impossibilidade de realizar um projeto pessoal, seja em virtude do peso das relações patriarcais, do papel subordinado da mulher ou da impossibilidade de encontrar caminhos alternativos aos horizontes atuais (ABRAMOVAY, 1988, p.40).

Assim o peso das relações familiares na decisão das jovens de permanecer no campo é indiscutível, sendo que a valorização das atividades desenvolvidas dentro da propriedade e a maior participação nas decisões familiares são importantes fatores no processo de tomada de decisão das jovens rurais.

\section{Opções de lazer no meio rural}

Para as jovens estudantes da Etec Jales as opções de lazer no meio rural estão ligadas às seguintes atividades: pescar, andar a cavalo, acompanhar programas na TV, internet, sair com os amigos (as), jogar futebol e jogar vôlei. Um número significativo de jovens (5 do total de 13) responderam que não participam de nenhuma atividade, segundo elas por falta de opção ou porque não identificam nenhum atrativo no meio rural.

Um considerável número de jovens tem a televisão como principal fonte de lazer, outras citaram que no tempo livre saem com a família ou visitam parentes na região.

A falta de atrativos de lazer no meio rural tem feito com que as jovens apresentem uma visão negativa deste meio e prefiram migrar para a cidade uma vez que identificam neste espaço maior número e melhores opções para diversão, estudo e trabalho. Para Godoy et al. (2010) os atrativos que se encontram nos centros urbanos para os jovens são muitos, como o acesso mais facilitado aos cursos de ensino médio, técnico e à universidade, empregos, renda, lazer, entre outros, que no meio rural dificilmente são encontrados.

\section{As jovens e a Etec Jales}

O aumento da escolarização é uma estratégia importante para concretização dos planos futuros por parte das jovens. Pesquisas como a de Carneiro (1998) revelam que os jovens atribuem importância à educação como uma possibilidade de uma remuneração melhor e de um trabalho menos pesado que a agricultura, uma vez que a atividade na roça não oferece estabilidade financeira e, frequentemente, nem garantias de direitos trabalhistas.

Para as jovens, filhas de agricultores familiares, os motivos que as levaram a estudar na Etec Jales, na maioria dos casos (7), se referem a fatores ligados à identificação com a área rural/curso; ao ensino de boa qualidade fornecido pela Escola (4); à influência de amigos e parentes; e à possibilidade de continuar estudos. Esses motivos são semelhantes em relação à escolha do curso na área agropecuária, sendo mais citados o gosto/identificação com a área (6); a realização do ensino médio/curso técnico de forma concomitante (2); e a influência de amigos/parentes (2).

Cultura Agronômica, Ilha Solteira, v.24, n.3, p.345-360, 2015 
Nas entrevistas realizadas com os pais (um dos casos foi realizado com o avô), estes manifestaram orgulho dos filhos estarem estudando para níveis mais avançados do que alcançaram, pois acreditam que a educação é uma maneira de terem uma vida melhor. São capazes de realizar sacrifícios para manter os filhos estudando:

\begin{abstract}
Sempre eu falo para elas, estudar! Tem que ser firme, né... procurar melhora e a gente ajuda, eu e a mulher sofre, trabalha, tem mês que tem que tirar para pagar para elas, às vezes paga aluguel, a Jo. paga 300 reais de aluguel, o serviço dela acho que é... mais 400 de faculdade [...] ela trabalha lá, 600 reais por mês, então não sobra para ela, então tem que tirar aqui e pagar lá... (pai da aluna 09, Santa Salete)
\end{abstract}

Os cursos voltados à área Agropecuária geralmente têm uma menor participação das meninas, uma vez que as relações de gêneros existentes no meio rural, no mercado de trabalho e dentro da escola, favorecem a distinção de tratamentos entre meninos e meninas, o que tem dificultado o investimento na área técnica pelas jovens e a maioria delas pretende continuar os estudos a partir de um curso superior.

Os conhecimentos adquiridos no meio rural foram imprescindíveis ao enfrentamento das dificuldades impostas às jovens pesquisadas que optaram por realizar um curso na área agropecuária. Estes conhecimentos, passados de geração em geração, contribuíram para a desenvoltura das alunas na escola, principalmente em aulas de campo. Para as jovens as experiências vividas no meio rural têm ajudado nas disciplinas do curso, entretanto, a aplicação dos conhecimentos adquiridos na Etec Jales dentro da propriedade tem sido comprometida principalmente pelas relações patriarcais e de gênero estabelecidas no meio rural: "Não aplico... meu pai já tem o jeito dele de trabalhar..." (aluna 48, 16 anos, Jales)

Em relação à avaliação do curso realizado na Etec Jales as jovens pesquisadas responderam que o curso é "bom" e que havia atendido às expectativas (7); outras (5) consideraram o curso "muito bom", tendo superado às expectativas; e somente uma aluna avaliou o curso como regular, pois considerava que faltava incentivar e motivar os alunos.

Nas atividades práticas desenvolvidas na Escola, muitas meninas encontram dificuldades em realizá-las, não porque não tenham condições e sim pela preferência que é dada aos meninos no desenvolvimento dessas atividades. Dessa forma, o aprendizado fica comprometido, sendo necessária maior intervenção da Etec Jales em relação a esses fatores, para que garantam às meninas a mesma qualidade de aprendizagem/ensino que é direcionada aos meninos.

A essência desse processo continua favorecendo os rapazes, uma vez que homens mais familiarizados com a lida do campo estão mais preparados para enfrentar os novos empreendimentos sozinhos. As mulheres não são encorajadas para tal, o espaço dado a elas na agricultura familiar continua ínfimo (JUNGUES, 2010). 


\section{O mercado de trabalho para as alunas da Etec Jales}

Embora a participação da mulher no mercado de trabalho seja crescente, o desequilíbrio das relações de gênero quanto às ocupações e renda ainda é preocupante. Segundo dados do IPEA (2010), as mulheres recebem menos e ocupam posições mais precárias, e são as mulheres que mais enfrentam dificuldades na inserção profissional em sua área de formação. Já o IBGE (2009) revela que as mulheres possuem rendas inferiores as dos homens em todos os estados brasileiros e em todos os níveis de escolaridade.

O número de jovens do sexo feminino que ingressam e conseguem concluir os estudos em escola técnica agrícola é extremamente menor do que os jovens do sexo masculino, uma vez que nesse espaço escolar e, posteriormente, no mercado de trabalho, as relações desiguais de gênero têm desestimulado a participação das meninas.

Para o Diretor da Etec Jales o ingresso de um número maior de meninas no vestibular do Curso Agropecuária está diretamente relacionado ao mercado de trabalho:

O fato que mais inibe as meninas estarem presentes na escola, acho que nem é a questão física [exigências do curso e do trabalho], mas elas não conseguem ver espelho de colocação no mercado de trabalho, são raros os casos das meninas que terminam o curso, tenham atrativos que estimulem alguém a vir... O mercado de trabalho não absorve as meninas com a mesma capacidade que absorve os meninos. Então o que estimula um aluno sair lá de Carneirinho... lá da Vila... e vir para escola é o primo dele, alguém que ele conhece que fez a Escola e tá trabalhando bem, em algum lugar ganhando bem. Ele não consegue ver a menina com este mesmo êxito (Diretor da Etec Jales).

Em pesquisa realizada por Begnami (2003), em relação ao ingresso na carreira profissional de técnico Agropecuário, foi constatado que $76 \%$ exercem funções compatíveis com a sua formação e entre as mulheres este percentual é de $58 \%$. Em outras ocupações, a maior taxa é das mulheres, $43 \%$ contra $27 \%$ dos homens. Estes dados reforçam a maior participação dos homens nas atividades profissionais voltadas à agropecuária.

Assim, o papel desempenhado pelas mulheres no campo não tem funcionado como atrativo para essas jovens estudantes, o que desencadeia preocupação em relação ao futuro e à carreira.

Em depoimento uma das jovens pesquisadas remete sua preocupação em relação à saída da escola e ao exercício profissional da carreira na área técnica, baseada no estágio que fez em uma empresa de insumos da região.

(...) Isto desmotiva muito a gente quando a gente sair daqui, por causa de emprego, é muito pequena a área pra mulher, só em usina de cana mesmo que a mulher está sendo empregada na área agrícola... as próprias mulheres dos produtores rurais não gostam, porque tá no campo, tá com o marido, vai olhar praga, elas não

Cultura Agronômica, Ilha Solteira, v.24, n.3, p.345-360, 2015 
gostam, e porque tá sozinho, né... O produtor não confia em técnica mulher... (aluna, 48, 16 anos, Jales)

O enfrentamento destes problemas relacionados à divisão sexual do trabalho existente, tem desestimulado muitas meninas, uma vez que sem possibilidade de encontrar uma vaga na área técnica, estas passam a prolongar a escolarização, a partir da obtenção de um diploma de curso superior, que normalmente não está relacionado à área agrícola, ou então preferem inserir-se em outras atividades, ditas como "femininas" para obtenção de uma renda fixa e consequentemente, uma maior autonomia em relação aos pais.

\section{Planos e projetos de vida das jovens rurais, alunas da Etec Jales}

Para Queiroz (2009) é possível perceber que a permanência dos sujeitos jovens no espaço rural está intrinsecamente ligada às condições de vida no lugar de origem. A ausência de estabilidade financeira, garantida por uma renda fixa, coloca os jovens atuantes neste contexto à margem da "decisão" de ficar ou partir. Passa a fazer parte dos seus planos continuar os estudos, trabalhar e gerar renda para alcançar seus objetivos.

Com relação ao que as jovens pretendem fazer após a conclusão do curso, 23,2\% das meninas disseram que pretendem realizar um curso superior. Dentre os cursos mais citados aparecem a Agronomia e as Ciências Biológicas, já a Medicina Veterinária, a Engenharia Civil e a Engenharia Ambiental também foram mencionadas, mas por um número menor de alunas. Somente duas afirmaram que pretendem trabalhar na área técnica que estavam formando e apenas uma das jovens manifestou interesse em trabalhar na propriedade dos pais. Isto demonstra um relativo desinteresse por parte das jovens em assumir a propriedade dos pais, talvez pela falta de perspectiva/possibilidade de que isso aconteça. A grande maioria tem preferência de prolongar a escolaridade, buscando obter um diploma de curso superior, que possa garantir, de certa forma, a independência em relação à família. A vontade de não permanecer na propriedade dos pais e de não trabalhar como agricultores(as), embora presente nas respostas dos jovens em geral, é mais evidente entre as repostas das meninas.

Eu daqui a 10 anos eu pretendo estar formada... em outro país, pretendo estar na África... ou num lugar bem longe daqui, lugar tipo o Nordeste... (aluna 48, 16 anos, Jales)

É comum entre os jovens a incerteza em relação ao futuro, uma vez que estão num período de constantes mudanças, o que leva muitas vezes a escolhas diferentes, mesmo quando decorrido pouco tempo entre uma fase da pesquisa e outra. Para as jovens essas incertezas parecem ser mais marcantes: duas das jovens entrevistadas mencionaram na primeira fase da pesquisa um determinado curso que fariam após a conclusão do curso e mudaram a opção na segunda fase da pesquisa (de Agronomia para Medicina, em um caso; e de Engenharia Civil para Ciências Biológicas em outro).

Verificou-se pela pesquisa realizada que a opção de sair do meio rural também é influenciada pelos pais, uma vez que eles próprios, frequentemente, desejam que as filhas permaneçam nos estudos para garantia de melhores condições para a família. 


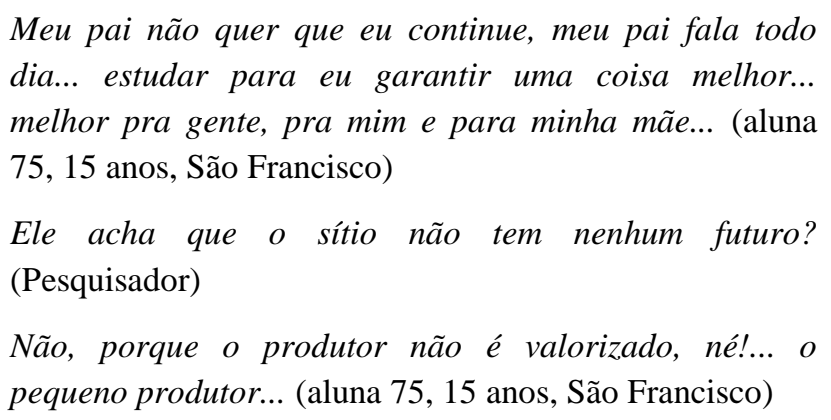

O interesse por parte das jovens em permanecer na propriedade foi quase totalmente ausente: apenas uma das jovens pesquisadas declarou o desejo de permanecer no meio rural e na propriedade dos pais, nos demais casos declararam que a propriedade continuaria sob a administração dos pais ou então seria assumida pelo irmão que ficou no estabelecimento. Este fato corrobora os resultados encontrados por Spanevello (2002), este autor revela que o filho homem é o herdeiro, o sucessor da unidade produtiva, e há um maior incentivo ao estudo e posterior migração da filha na busca de um diploma e uma profissão urbana.

\section{CONSIDERAÇÕES FINAIS}

As jovens estudantes da Etec Jales têm no prolongamento da escolarização a busca por melhores condições de vida. De modo geral as jovens não têm a intenção de assumir a propriedade dos pais e seus planos para o futuro remetem ao ingresso em um curso superior ou conseguir um emprego fora do meio rural. Este fato pode comprometer a reprodução da agricultura familiar, especialmente quando não há irmãos dispostos a assumir a direção do estabelecimento. É necessário repensar as condições desiguais que vivem meninos e meninas no meio rural, pois em grande parte as causas que têm levado essas jovens a migrarem para cidades decorrem da falta de oportunidades que se deparam no próprio interior da família, embora os fatores econômicos gerais vivenciados pelas famílias também não devam ser desprezados.

A trajetória de vida dessas jovens é marcada pelas relações desiguais de gênero, impostas culturalmente, mas que aparecem como se fossem algo natural. Embora venham ocorrendo algumas mudanças no período recente, ainda faltam muitos aspectos para que as relações entre homens e mulheres sejam igualitárias. É imprescindível a mudança em relação ao lugar ocupado pela jovem mulher no meio rural e as ações das políticas públicas devem contribuir para garantir os direitos desse segmento social, marcado pela invisibilidade de seu trabalho e de outras dimensões de sua vida.

A Escola tem condições de desempenhar um importante papel na formação dos(as) jovens, mas é necessário considerar todos os aspectos relacionados às diferenças e especificidades existentes entre moças e rapazes neste âmbito, garantindo uma maior participação/integração das jovens nas atividades voltadas ao campo, para que as mesmas possam assimilar na prática, os conhecimentos técnicos da área agropecuária, contribuindo para condições mais igualitárias de competição no mercado de trabalho.

Cultura Agronômica, Ilha Solteira, v.24, n.3, p.345-360, 2015 


\section{AGRADECIMENTOS}

À CAPES (Coordenação de Aperfeiçoamento de Pessoal de Nível Superior) pelo apoio concedido por meio da bolsa de estudos e à Fapesp que concedeu auxílio para o desenvolvimento da pesquisa.

\section{REFERÊNCIAS BIBLIOGRÁFICAS}

ABRAMOVAY, R.; SILVESTRO, M.; CORTINA, N.; BALDISSERA, I. T.; FERRARI, D.; TESTA, V. M . Juventude e agricultura familiar: desafios dos novos padrões sucessórios. Brasília: Unesco, 1998. 104 p.

BEGNAMI, J. B. Formação pedagógica de monitores das Escolas Famílias Agrícolas e Alternâncias: um estudo intensivo dos processos formativos de cinco monitores. 2003. 134 f. Dissertação (Mestrado em Ciências da Educação) - Faculdade de Ciências e Tecnologia da Universidade Nova de Lisboa, Diplôme d’Université Francois Rabelais de Tours, Belo Horizonte, 2003.

BRUMER, A.; PAULILO, M. I. As agricultoras do sul do Brasil. Estudos Feministas, Florianópolis, v. 12, n. 1, p.360, 2006.

CARNEIRO, M. J. O ideal rurbano: campo e cidade no imaginário de jovens rurais. In: SILVA, F. C. T.; SANTOS, R.; COSTA, L. F. C., (Orgs.). Mundo rural e política: ensaios interdisciplinares. Rio de Janeiro: Editora Campus, 1998. cap. 4, p. 97-117.

CASTRO, E. G. Entre Ficar e Sair: uma etnografia da construção social da categoria jovem rural. Rio de Janeiro, 2004. 444 p. Tese (Doutorado em Antropologia Social) Museu Nacional, Universidade Federal do Rio de Janeiro, Rio de Janeiro, 2004.

CENTRO PAULA SOUZA Escolas técnicas. 2008. Disponível em: <http://www.ceeteps.br/Ete/Escolas/S_J_Rio_Preto/Jales_ETE_Dr_Jose_Luiz.html>. Acesso em: 04 abr. 2010.

ETEC JALES. A Escola. Disponível em: <http://www.etejales.com.br>. Acesso em: 24 jun. 2010 .

GODOY, C. M. T.; PÉREZ, F. I. C.; WIZNIEWSKY, J. G.; GUEDES, A. C.; MORAES, C.S. Juventude rural, envelhecimento e o papel da aposentadoria no meio rural: a realidade do município de Santa Rosa/RS. In: CONGRESSO SOCIEDADE BRASILEIRA DE ECONOMIA, ADMINISTRAÇÃO E SOCIOLOGIA RURAL, 48, 2010, Campo Grande. Anais... Campo Grande: SOBER, 2010. p. 25-32. CD-ROM. 
IBGE - INSTITUTO BRASILEIRO DE GEOGRAFIA E ESTATÍSTICA. População ocupada, 2009. Disponível em: 〈http://www.ibge.gov.br〉. Acesso em: 14 mar. 2011.

IPEA. Políticas Sociais: acompanhamento e análise. Brasília, n. 18, 2010. 98 p.

JUNGUES, D. M. Jovens rurais de Iracema do Oeste. 2010, 80 p Dissertação (Mestrado em Desenvolvimento Regional e Agronegócio) - Universidade Estadual do Oeste do Paraná. Toledo, 2010.

MARTINS, M. Relações de gênero e geração em um assentamento rural de reforma agrária: Sociabilidade e poder. Fazendo Gênero 8 - Corpo, Violência e Poder. Florianópolis, 2008. Disponível em: <http://www.fazendogenero.ufsc.br/8/sts/ST15/Maira_Martins_15.pdf>. Acesso em: 13 dez. 2010.

MENEZES, I. G. Educação escolar e identidade cultural de jovens rurais: uma proposta de pesquisa. Seminário de Estudos Culturais, Identidades e Relações Interétnicas. Universidade Federal de Sergipe. São Cristóvão, Agosto de 2009. Disponível em: <http://www.pos.ufs.br/antropologia/seciri/down/GT_06/Isabela_Goncalves_de_Menezes.p df>. Acesso em: 14 mai. 2010.

OLIVEIRA, E. F. Colaboração Educacional como gerador de ações educativas críticas na formação de professores da Educação Básica do Campo. Pedagogia: a revista do curso, São Paulo, ano 2, n. 4, p.35, 2003.

PAIS, J. M. Vida cotidiana - enigmas e revelações. São Paulo: Cortez, 2003. 117 p.

PETINARI, R. A.; TERESO, M. J. A.; BERGAMASCO, S. M. P. P. A importância da fruticultura para os agricultores familiares da região de Jales-SP. Revista Brasileira de Fruticultura, Jaboticabal, v. 30, n. 2, p.356-360, 2008.

QUEIROZ, T. L. B. A Territorialização da Via Campesina na Paraíba. 2009. 86 p. Monografia (Graduação em Geografia) - Universidade Federal da Paraíba, João Pessoa, 2009.

SÃO PAULO - Secretaria de Agricultura e Abastecimento. Coordenadoria de Assistência Técnica Integral. Instituto de Economia Agrícola. Levantamento censitário de unidades de produção agrícola do Estado de São Paulo - LUPA 2008. São Paulo: SAA/CATI/IEA, 2012. Disponível em: <http://www.cati.sp.gov.br/projetolupa>. Acesso em: 23 abr. 2014.

SPANEVELLO, R. M.; LAGO, A.; VELA, H. G. Juventude rural: associativismo e lazer como forma de desenvolvimento social. In: CONGRESSO DA ASSOCIAÇÃO LATINOAMERICANA DE SOCIOLOGIA RURAL, 6., 2002, Porto Alegre. Anais... Porto Alegre: UFRGS, 2002. p. 14-22. CD-ROM.

Cultura Agronômica, Ilha Solteira, v.24, n.3, p.345-360, 2015 
STROPASOLAS, V. L. O mundo rural no horizonte dos jovens. Florianópolis: UFSC, 2006. $92 \mathrm{p}$.

TONDATO, C.; CASSUCCI, A. R.; ANDRADE, J. D. A pluriatividade na agricultura familiar do município de Jales - SP: o estudo de caso de duas comunidades rurais. In: CONGRESSO SOCIEDADE BRASILEIRA DE ECONOMIA, ADMINISTRAÇÃO E SOCIOLOGIA RURAL, 48, 2010, Campo Grande. Anais... Campo Grande: SOBER, 2010. p. 13-14. CD-ROM. 